Original

\title{
New acid dyes and their metal complexes based on substituted phenols for leather: Synthesis, characterization and optical studies
}

\author{
Ghulam Hussain $^{\mathrm{a}}$, Nasir Abass ${ }^{\mathrm{b}}$, Ghulam Shabir ${ }^{\mathrm{b}}$, Makshoof Athar ${ }^{\mathrm{a}}$, Aamer Saeed ${ }^{\mathrm{b}, *}$, \\ Rashid Saleem ${ }^{\mathrm{c}}$, Farman Ali $^{\mathrm{d}}$, Misbahul Ain Khan ${ }^{\mathrm{e}}$ \\ ${ }^{a}$ Institute of Chemistry, University of the Punjab, Lahore, Pakistan \\ ${ }^{\mathrm{b}}$ Department of Chemistry, Quaid-I-Azam University, Islamabad 45320, Pakistan \\ ${ }^{\mathrm{c}} R \& D$ Manager Shafi Reso Chem Lahore Pakistan \\ ${ }^{\mathrm{d}}$ Department of Chemistry, Hazara University, Mansehra 21300, Pakistan \\ ${ }^{\mathrm{e}}$ Department of Chemistry, the Islamia University of Bahawalpur, Bahawalpur, Pakistan \\ Received 12 October 2016; accepted 2 March 2017 \\ Available online 6 August 2017
}

\begin{abstract}
The present investigation deals with synthesis of new acid dyes from 4-amino-1-(4-sulfophenyl)-3-methyl-5-pyrazolone and phenol derivatives and their metal complexes (Cu (II) and Fe (II)). The phenol derivatives include 4-chlorophenol, 4-nitrophenol, 4-hydroxybenzene sulfonic acid, 2-nitrophenol-4-sulfonic acid, resorcinol and bisphenol A and bisphenol S. The newly synthesized dyes were applied to crust leather to assess their dyeing properties. The fastness properties of unmetallized dyes were less as compared to metal complexes due to the strong interaction of metals with leather protein. The structures of these dyes were also confirmed by UV, FTIR and NMR studies.

(C) 2017 Universidad Nacional Autónoma de México, Centro de Ciencias Aplicadas y Desarrollo Tecnológico. This is an open access article under the CC BY-NC-ND license (http://creativecommons.org/licenses/by-nc-nd/4.0/).
\end{abstract}

Keywords: 4-Amino-1-(4-sulfophenyl)-3-methyl-5-pyrazolone; Phenol derivatives; Metal complexes; Applications

\section{Introduction}

Azo compounds are non-naturally occurring nitrogen compounds continuously receiving attention in scientific research (Kirkan \& Gup, 2008; Otutu, 2013; Seferoğlu, 2009). Azo dyes constitute the largest group of Azo compounds and the most widely used colorants in the industry. Several derivatives of pyrazole (azo) were the subject of research because of a variety of applications. The applications of the azo dyes include their use in coloring fibers, due to their affinity for wool and silk (Patel \& Patel, 2011), photoelectronics (Sekar, 1999), optical storage technology (Wang, Shen, \& Xu, 2000), biological reactions (Weglarz-Tomczak \& Gorecki, 2012), printing systems (Abe, Mano, Yamaya, \& Tomotake, 1999; Dharmalingam, Ramasamy, \& Balasuramanian, 2011) as well as in analytical

\footnotetext{
* Corresponding author.

E-mail addresses: asaeed@qau.edu.pk, aamersaeed@yahoo.com (A. Saeed).

Peer Review under the responsibility of Universidad Nacional Autónoma de México.
}

(Abdalla, El-Haty, Adam, \& Hassan, 2013; Amin, Mohammed, \& Mousa, 2003) and food chemistry (Almeida, Stephani, Dos Santos, \& Oliveira, 2009). Beside these many azo compounds have been synthesized with an industrial and medical aim. The coordination complexes of transition metals with azo-ligands are also focus of the current attraction due to the interesting physical, chemical, photophysical and photochemical, catalytic and different material properties. Metal complex dyes play a very important role in the textile industry. Chromium, Cr (III) and cobalt Co (III) complexes are used most frequently for the dyeing of wool and synthetic polyamides (Kocaokutgen, Erdem, \& Gümrükçgüoglu, 1998).

Photophysical and coloristic properties of the dyes are modified in the case of aggregate formation (molecular association) in solution. The self-association of dyes in solution is due to the interactions by Van der Waals forces, hydrogen bonds and hydrophobic interactions (Radulescu-Grad, Muntean, Todea, Verdes, \& Andelescu, 2015). The dye aggregation is affected by parameters such as dye concentration, dye structure, $\mathrm{pH}$, temperature, solvents and ionic strengths (Goftar, Moradi, \& Kor, 2014). 
In the present work, two new series of azo-dyes, having $\mathrm{Fe}^{+2}$ and $\mathrm{Cu}^{2+}$ as metalizing ion were synthesized, characterized and applied to leather. At the same time, spectrophotometric analysis was also performed for the qualitative study of ligand acid dyes and their metal complex.

\section{Experimental}

\subsection{Materials and methods}

All commercial products were purchased from SigmaAldrich. Solvents were purified and dried by the standard methods. Melting points were determined in open capillary tubes on a Stuart melting point apparatus. The FTIR spectra were run in the single beam Nicolet IR 100 (Fourier-Transform); while UV of all the samples were taken in water using UV-Genesys spectrophotometer. Their mass spectral data were obtained from waters GCT premier spectrometer. The ${ }^{1} \mathrm{H}$ NMR and ${ }^{13} \mathrm{C}$ NMR spectra were recorded in DMSO- $\mathrm{d}_{6}$ using NMR Bruker DPX 400 spectrophotometer operating at 300 and $75 \mathrm{MHz}$ for ${ }^{1} \mathrm{H}$ and ${ }^{13} \mathrm{C}$ NMR respectively. TMS was used as internal standard with the deuterium signal of the solvent as the lock and chemical shifts $\delta$ recorded in ppm. The elemental analysis $(\mathrm{C}, \mathrm{H}, \mathrm{N}, \mathrm{S})$ of the compounds was performed using Flash EA 1112 elemental analyzer while the $\mathrm{pH}$ was monitored using Portable $\mathrm{pH}$ Meter Model PHB4. Compounds were routinely checked by TLC on silica gel $\mathrm{G}$ plates using three different eluting solvents depending on the polarity disparity. The solvent systems are petroleum ether:chloroform $(9: 1, \mathrm{v} / \mathrm{v})$, petroleum ether:chloroform $(6: 4$, $\mathrm{v} / \mathrm{v})$ and chloroform:methanol $(9: 1, \mathrm{v} / \mathrm{v})$. Also, the developed plates were visualized using a UV lamp for the presence of spots and $R_{f}$ values were duly calculated. All of the crude products were isolated as solids and purified. Fastness to light was assessed in accordance with BS 1006-1978. Rubbing fastness was checked with an Atlas Crock meter in accordance with AATCC TM 8-1961 and the wash fastness was determined according to ISO: 765-1979 (Maradiya \& Patel, 2002; Sakoma, Bello, \& Yakubu, 2012).

\subsection{General procedure for the synthesis of 1-(p-sulphophenyl)-3-methyl-5-pyrazolone based acid dyes}

Synthesis of acid dyes and their metal complexes involves three-step procedure which is as follows.

\subsubsection{Nitrosation of}

p-sulphophenyl-3-methyl-5-pyrazolone (SPMP)

1-(p-sulfophenyl)-3-methyl-5-pyrazolone (1) (25.4 g, $0.1 \mathrm{~mol})$ was suspended in $\mathrm{H}_{2} \mathrm{O}(250 \mathrm{ml})$. Hydrochloric acid $(45 \mathrm{ml})$ was added to this well stirred suspension. The reaction mixture was cooled to $0-5^{\circ} \mathrm{C}$ in an ice bath. A solution of $\mathrm{NaNO}_{2}(6.9 \mathrm{~g}, 0.1 \mathrm{~mol})$ in $\mathrm{H}_{2} \mathrm{O}(25 \mathrm{ml})$ previously cooled to $0{ }^{\circ} \mathrm{C}$, was then added over a period of $35 \mathrm{~min}$ with stirring. The stirring was continued for an hour maintaining the same temperature, with a positive test for nitrous acid. Later on the excess of nitrous acid was destroyed with required amount of sulphamic acid. The nitroso (oxime) was filtered after salting out. Then oxime was reduced by stirring in $200 \mathrm{ml}$ water containing $85 \mathrm{ml}$ $\mathrm{HCl}$ and $23 \mathrm{~g}$ zinc metal at boil for $4 \mathrm{~h}$. On completion of reaction, $\mathrm{pH}$ of the reaction mixture was raised to 9 with $6 \mathrm{~N} \mathrm{NaOH}$, and precipitated the 1-(p-methylphenyl)-3-methyl-4-amino pyrazolones.

\subsubsection{Diazotization and coupling with phenol derivatives}

To the well stirred ice jacketed aqueous solution $(2.69 \mathrm{~g})$ of 1 ( $p$-sulphophenyl)-3-methyl-4-amino pyrazolone $\left(\right.$ at $0-5{ }^{\circ} \mathrm{C}$ ) was added conc. $\mathrm{HCl}(3.5 \mathrm{ml})$ and sodium nitrite solution $(0.7 \mathrm{~g}$ in $2 \mathrm{ml} \mathrm{H}_{2} \mathrm{O}$ ). The reaction mixture was vigorously stirred for $1 \mathrm{~h}$ at the above mentioned temperature to obtain the diazonium salt of 1-(p-sulphophenyl)-3-methyl-4-amino pyrazolone. The diazonium compound formed in this way was coupled to various coupler mentioned previously to synthesize our dyes. Thus $1.285 \mathrm{~g}(0.010 \mathrm{~mol}) 4$-chlorophenol (5a) was dissolved in $200 \mathrm{ml}$ water containing $0.45 \mathrm{~g} \mathrm{NaOH}$ and coupled with prepared diazo. The coupling was facilitated using sodium carbonate as an acid binding agent. The reaction mixture was given $4-5 \mathrm{~h}$ to complete the coupling at $30-35^{\circ} \mathrm{C}$. The dye was cooled to room temperature. Its $\mathrm{pH}$ was reduced to $4.5 \mathrm{by} \mathrm{HCl}$ and filtered. The cake was dried in oven at $70-75^{\circ} \mathrm{C}$ till constant weight. By adopting the same procedure other dyes $\mathbf{6 b}-\mathbf{f}$ were prepared from couplers $\mathbf{5 b - f}$ as shown in Scheme 1.

\subsubsection{Metallization of acid dyes}

For the synthesis of metal complexes (iron complex), $\mathrm{pH}$ of $25 \mathrm{ml}(0.005 \mathrm{~mol})$ of dye $\mathbf{6 a}$ was reduced to 6.5 with $\mathrm{HCl}$. Then it was heated to $70^{\circ} \mathrm{C}$ and to it $5 \mathrm{ml}\left(0.005 \mathrm{~mol} \mathrm{Fe}^{2+}\right)$ solution of ferrous sulfate $\left(\mathrm{FeSO}_{4} \cdot 7 \mathrm{H}_{2} \mathrm{O}\right)$ was added drop wise. Mixing and heating at this temperature was continued for further 1.0 hour till the metallization was completed, as shown by the comparative TLC. The dye was cooled to room temperature; its $\mathrm{pH}$ was reduced to 1.0 with conc. $\mathrm{HCl}$. Then it was salted out with sodium chloride, filtered and dried in oven at $80^{\circ} \mathrm{C}$ till constant weight.

Similarly, copper (II) complexes of dye 6a were prepared by treating dye with $\mathrm{CuSO}_{4} \cdot 5 \mathrm{H}_{2} \mathrm{O}$ at $65-70{ }^{\circ} \mathrm{C}$ with metal to ligand mole ratio $1: 1$. In this way complexes $\mathbf{7 a - l}$ were synthesized from respective dye ligands (see supplementary information).

2.2.3.1. $\boldsymbol{\sigma} \boldsymbol{a}\left(\mathrm{C}_{16} \mathrm{H}_{13} \mathrm{ClN}_{4} \mathrm{O}_{5} \mathrm{~S}\right)$. Orange, $(76 \%)$. $\lambda_{\max }(\mathrm{nm}): 460$. FTIR $\left(\mathrm{KBr}, \mathrm{cm}^{-1}\right) v_{\max }$ : 3255 (OH str.), $3050(\mathrm{C}=\mathrm{C}-\mathrm{H}$ str.), 2927 ( $\mathrm{CH}_{2}$ str.), 1653 ( $\mathrm{C}=\mathrm{O}$ str.), 1595, 1541 ( $\mathrm{C}=\mathrm{C}$ aromatic, $\mathrm{C}=\mathrm{N}), 1498(\mathrm{~N}=\mathrm{N}$ str. $), 1422,1340\left(\mathrm{SO}_{3} \mathrm{H}\right.$ str., $\mathrm{CH}_{2}$ bend. $)$, 1236, 1155 (C-C, C-O str.), $1000(\mathrm{~S}=\mathrm{O}$ str.), $833(\mathrm{Ar}-\mathrm{H}), 790$ (C-Cl str.). ${ }^{1} \mathrm{H}$ NMR $(300 \mathrm{MHz}$, DMSO-d 6 ) $\delta: 8.07(1 \mathrm{H}, \mathrm{d}$, $J=2.35 \mathrm{~Hz}), 7.95(2 \mathrm{H}, \mathrm{d}, J=8.6 \mathrm{~Hz}), 7.83-7.90(1 \mathrm{H}, \mathrm{m}), 7.68$ $(2 \mathrm{H}, \mathrm{d}, J=8.6 \mathrm{~Hz}), 6.65(1 \mathrm{H}, \mathrm{d}, J=9.1 \mathrm{~Hz}), 2.20(3 \mathrm{H}, \mathrm{s}) .{ }^{13} \mathrm{C}$ NMR (75 MHz DMSO-d 6 ) $\delta$ (ppm): 158.54, 156.64, 147.93, 147.37, 143.21, 139.93, 125.43, 124.41, 119.45, 118.06, 116.22

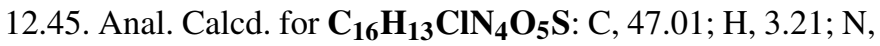
13.71; S, 7.84. Found: C, 47.05; H, 3.30; N, 13.59; S, 7.79.

2.2.3.2. $\boldsymbol{\sigma} \boldsymbol{b}\left(\mathrm{C}_{16} \mathrm{H}_{13} \mathrm{~N}_{5} \mathrm{O}_{7} \mathrm{~S}\right)$. Dark Brown, (83\%). $\lambda_{\max }(\mathrm{nm})$ : 480. FTIR ( $\left.\mathrm{KBr}, \mathrm{cm}^{-1}\right) v_{\max }: 3388$ (OH str.), $2924\left(\mathrm{CH}_{2}\right.$ str.), 


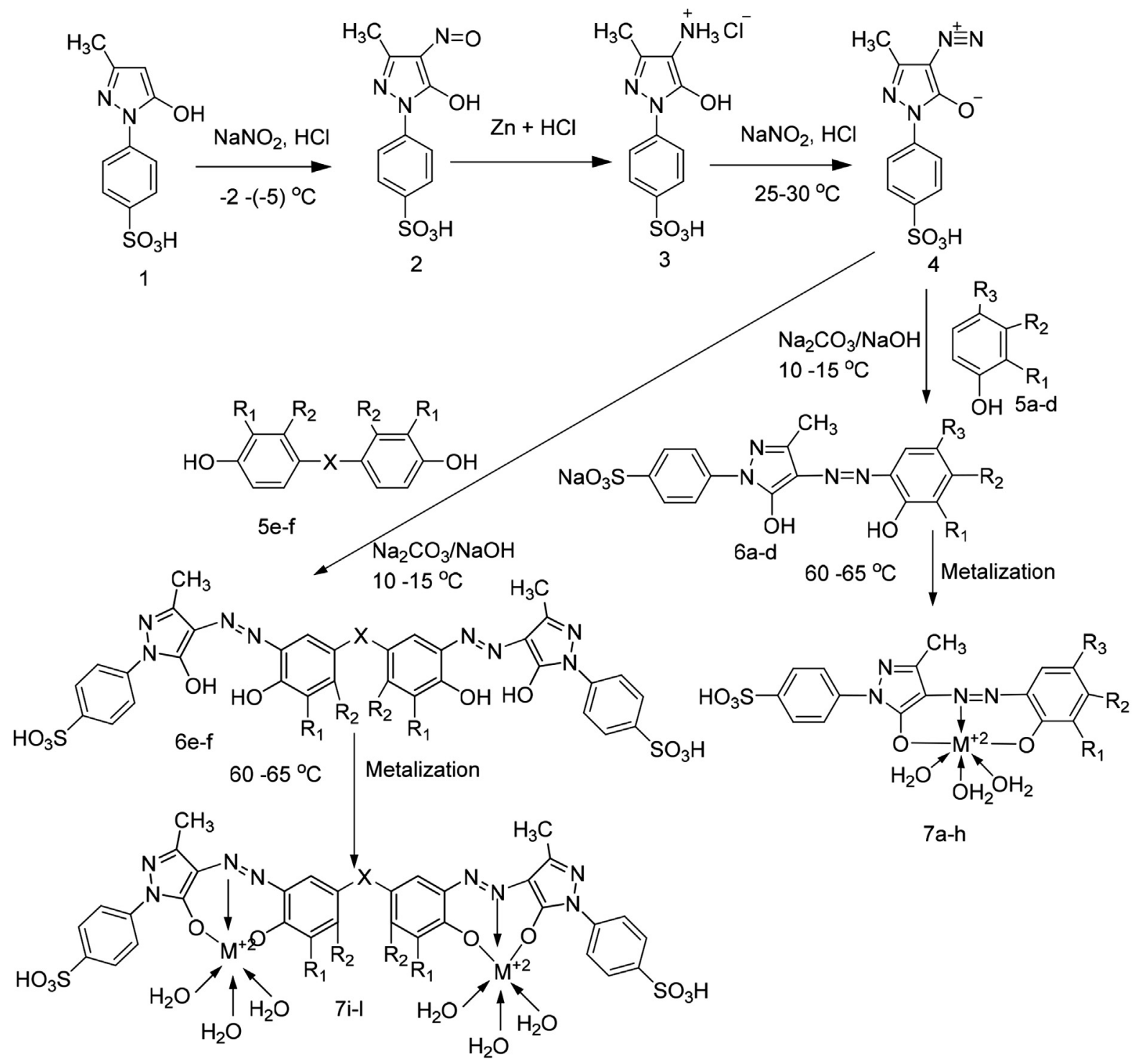

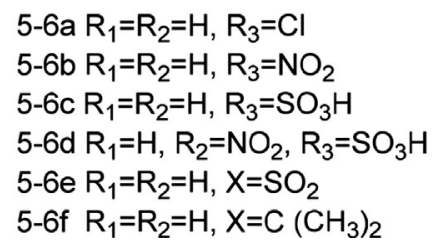

7a $\mathrm{R}_{1}=\mathrm{R}_{2}=\mathrm{H}, \mathrm{R}_{3}=\mathrm{Cl}, \mathrm{M}=\mathrm{Fe}(\mathrm{II})$, 7c $\mathrm{R}_{1}=\mathrm{R}_{2}=\mathrm{H}, \mathrm{R}_{3}=\mathrm{NO}_{2}, \mathrm{M}=\mathrm{Fe}$ (II), 7e $\mathrm{R}_{1}=\mathrm{R}_{2}=\mathrm{H}, \mathrm{R}_{3}=\mathrm{SO}_{3} \mathrm{H}, \mathrm{M}=\mathrm{Fe}$ (II), $7 \mathrm{~g} \mathrm{R}_{1}=\mathrm{H}, \mathrm{R}_{2}=\mathrm{NO}_{2}, \mathrm{R}_{3}=\mathrm{SO}_{3} \mathrm{H}, \mathrm{M}=\mathrm{Fe}$ (II) 7i $\mathrm{R}_{1}=\mathrm{R}_{2}=\mathrm{H}, \mathrm{X}=\mathrm{SO}_{2}, \mathrm{M}=\mathrm{Fe}$ (II), $7 \mathrm{k} \mathrm{R}_{1}=\mathrm{R}_{2}=\mathrm{H}, \mathrm{X}=\mathrm{C}\left(\mathrm{CH}_{3}\right)_{2}, \mathrm{M}=\mathrm{Fe}$ (II), 7b R $\mathrm{R}_{1}=\mathrm{R}_{2}=\mathrm{H}, \mathrm{R}_{3}=\mathrm{Cl}, \quad \mathrm{M}=\mathrm{Cu}$ (II), $7 \mathrm{~d} \mathrm{R} \mathrm{R}_{1}=\mathrm{R}_{2}=\mathrm{H}, \mathrm{R}_{3}=\mathrm{NO}_{2}, \mathrm{M}=\mathrm{Cu}$ (II), $7 f \mathrm{R}_{1}=\mathrm{R}_{2}=\mathrm{H}, \mathrm{R}_{3}=\mathrm{SO}_{3} \mathrm{H}, \mathrm{M}=\mathrm{Cu}$ (II), ), 7h $\mathrm{R}_{1}=\mathrm{H}, \mathrm{R}_{2}=\mathrm{NO}_{2}, \mathrm{R}_{3}=\mathrm{SO}_{3} \mathrm{H}, \mathrm{M}=\mathrm{Cu}$ (II), 7j $\mathrm{R}_{1}=\mathrm{R}_{2}=\mathrm{H}, X=\mathrm{SO}_{2}, \mathrm{M}=\mathrm{Cu}$ (II), 7I $R_{1}=R_{2}=H, X=C\left(\mathrm{CH}_{3}\right)_{2}, M=C u$ (II),

Scheme 1. Synthesis of ligand acid dyes $\mathbf{6 a}-\mathbf{f}$ and their Fe (II) and Cu (II) complexes (7a-1).

$1666(\mathrm{C}=\mathrm{C}$ str. $), 1593(\mathrm{C}=\mathrm{C}$ aromatic, $\mathrm{C}=\mathrm{C}), 1498,1476(\mathrm{~N}=\mathrm{N}$, $\mathrm{NO}_{2}$ str.), 1267, 1172 (C-O str.), 1034 (C-OC str.), 821 (ArH). ${ }^{1} \mathrm{H}$ NMR $\left(300 \mathrm{MHz}, \mathrm{DMSO}-\mathrm{d}_{6}\right) \delta: 8.15(1 \mathrm{H}, \mathrm{d}, J=2.4 \mathrm{~Hz})$, $7.942(2 \mathrm{H}, \mathrm{d}, J=8.7 \mathrm{~Hz}), 7.81-7.92(1 \mathrm{H}, \mathrm{m}), 7.65(2 \mathrm{H}, \mathrm{d}$, $J=8.7 \mathrm{~Hz}), 6.38(1 \mathrm{H}, \mathrm{d}, J=9.3 \mathrm{~Hz}), 2.27(3 \mathrm{H}, \mathrm{s}) .{ }^{13} \mathrm{C} \mathrm{NMR}$ (75 MHz DMSO-d 6 ) $\delta$ (ppm): 158.0, 155.28, 148.32, 147.57, 144.58, 138.72, 128.18 126.86, 126.24, 118.19, 117.06, 116.17, 12.14. Anal. Calcd. for $\mathbf{C}_{\mathbf{1 6}} \mathbf{H}_{\mathbf{1 3}} \mathbf{N}_{\mathbf{5}} \mathbf{O}_{7} \mathbf{S}$ : C, 45.83; H, 3.12; N, 16.70, S, 7.64. Found: C, 45.78; H, 3.20; N, 16.58, S, 7.57.

2.2.3.3. $6 c\left(\mathrm{C}_{16} \mathrm{H}_{14} \mathrm{~N}_{4} \mathrm{O}_{8} \mathrm{~S}_{2}\right)$. Orange, (84\%). $\lambda_{\max }(\mathrm{nm}): 460$. FTIR (KBr, cm $\left.{ }^{-1}\right) v_{\max }$ : 3389 (OH str), 3086 (C=C-H str.), 1638 ( $\mathrm{N}-\mathrm{H}$ bend. $), 1619,1597(\mathrm{C}=\mathrm{C}$ aromatic $), 1541(\mathrm{~N}=\mathrm{N}$ str. $)$,
1500 (N-H bend.), 1340 ( $\mathrm{SO}_{3} \mathrm{H}, \mathrm{CH}_{2}$ str.), 1185 (C-O str.), 818 $(\mathrm{Ar}-\mathrm{H}) .{ }^{1} \mathrm{H}$ NMR $\left(300 \mathrm{MHz}, \mathrm{DMSO}-\mathrm{d}_{6}\right) \delta: 11.87(1 \mathrm{H}, \mathrm{s}, \mathrm{O}-\mathrm{H})$, $8.10(1 \mathrm{H}, \mathrm{d}, J=2.6 \mathrm{~Hz}), 7.93(2 \mathrm{H}, \mathrm{d}, J=8.6 \mathrm{~Hz}), 7.79-7.90(1 \mathrm{H}$, $\mathrm{m}), 7.67(2 \mathrm{H}, \mathrm{d}, J=8.6 \mathrm{~Hz}), 6.90\left(1 \mathrm{H}, \mathrm{s}, \mathrm{SO}_{3} \mathrm{H}\right), 6.58(1 \mathrm{H}$, $\mathrm{d}, J=9.5 \mathrm{~Hz}), 2.27(3 \mathrm{H}, \mathrm{s}) .{ }^{13} \mathrm{C}$ NMR $(75 \mathrm{MHz}$ DMSO-d 6$) \delta$ (ppm): 159.12, 156.48, 147.72, 147.17, 145.23, 141.33, 138.62, 125.68, 124.42, 117.19, 116.96, 116.43 11.81. Anal. Calcd. for $\mathbf{C}_{16} \mathbf{H}_{14} \mathbf{N}_{4} \mathbf{O}_{8} \mathbf{S}_{2}$ : C, 42.29; H, 3.11; N, 12.33, S: 14.11. Found: C, 42.24; H, 3.20; N, 12.21, S: 14.04 .

2.2.3.4. $6 \boldsymbol{d}\left(\mathrm{C}_{16} \mathrm{H}_{13} \mathrm{~N}_{5} \mathrm{O}_{10} \mathrm{~S}_{2}\right)$. Orange, (81\%). $\lambda_{\max }(\mathrm{nm}): 520$. FTIR (KBr, cm $\left.{ }^{-1}\right) v_{\max }: 3449$ (OH str.), 3050 (C=C-H str.), $1653(\mathrm{C}=\mathrm{C}$ str. $\mathrm{NH}$ bend $), 1619,1541(\mathrm{C}=\mathrm{C}$ aromatic $), 1498$ 
( $\mathrm{N}=\mathrm{N}$ str. $), 1338\left(\mathrm{SO}_{3} \mathrm{H}, \mathrm{CH}_{2}\right.$ str. $), 1183$ (C-O str.), $1008(\mathrm{~S}=\mathrm{O})$, $840(\mathrm{Ar}-\mathrm{H}) .{ }^{1} \mathrm{H}$ NMR $\left(300 \mathrm{MHz}, \mathrm{DMSO}-\mathrm{d}_{6}\right) \delta: 11.33(1 \mathrm{H}, \mathrm{s}$, $\mathrm{O}-\mathrm{H}), 8.15(1 \mathrm{H}, \mathrm{d}, J=2.4 \mathrm{~Hz}), 7.99(1 \mathrm{H}, \mathrm{d}, J=2.4 \mathrm{~Hz}), 7.922$ $(2 \mathrm{H}, \mathrm{d}, J=8.7 \mathrm{~Hz}), 7.63(2 \mathrm{H}, \mathrm{d}, J=8.7 \mathrm{~Hz}), 2.23(3 \mathrm{H}, \mathrm{s}) .{ }^{13} \mathrm{C}$ NMR (75 MHz DMSO-d 6 ) $\delta$ (ppm): 157.05, 156.28, 149.25, 147.63, 144.28, 142.76, 140.92, 127.16, 125.54, 119.19, 116.56, 115.20 12.14. Anal. Calcd. for $\mathbf{C}_{\mathbf{1 6}} \mathbf{H}_{\mathbf{1 3}} \mathbf{N}_{\mathbf{5}} \mathbf{O}_{\mathbf{1 0}} \mathbf{S}_{\mathbf{2}}: \mathrm{C}, 38.48 ; \mathrm{H}$, 2.62 ; N, 14.02; S, 12.84. Found: C, 38.37; H, 2.69; N, 13.96; S, 12.88 .

2.2.3.5. бe $\left(\mathrm{C}_{32} \mathrm{H}_{26} \mathrm{~N}_{8} \mathrm{O}_{12} \mathrm{~S}_{3}\right)$. Orange, (80\%). $\lambda_{\max }(\mathrm{nm}): 420$. FTIR $\left(\mathrm{KBr}, \mathrm{cm}^{-1}\right) v_{\max }: 3395(\mathrm{OH}, \mathrm{NH}$ str. $), 3050(\mathrm{C}=\mathrm{C}-\mathrm{H}$ str. $), 2926\left(\mathrm{CH}_{2}\right.$ str. $), 1619,1586(\mathrm{C}=\mathrm{C}$ aromatic, $\mathrm{C}=\mathrm{N}), 1498$ $(\mathrm{N}=\mathrm{N}$ str. $), 1125(\mathrm{C}-\mathrm{O}$ str. $), 1008(\mathrm{~S}=\mathrm{O}), 872(\mathrm{Ar}-\mathrm{H}) .{ }^{1} \mathrm{H}$ NMR $\left(300 \mathrm{MHz}, \mathrm{DMSO}_{6}\right) \delta$ : $11.67(1 \mathrm{H}, \mathrm{s}, \mathrm{O}-\mathrm{H}), 7.91(2 \mathrm{H}, \mathrm{d}$, $J=8.7 \mathrm{~Hz}), 7.81-7.92(1 \mathrm{H}, \mathrm{m}), 7.69(2 \mathrm{H}, \mathrm{d}, J=8.7 \mathrm{~Hz}), 6.90$ $(1 \mathrm{H}, \mathrm{d}, J=9.4 \mathrm{~Hz}), 6.78(1 \mathrm{H}, \mathrm{s}), 6.62\left(1 \mathrm{H}, \mathrm{s}, \mathrm{SO}_{3} \mathrm{H}\right), 6.59(1 \mathrm{H}$, $\mathrm{d}, J=9.4 \mathrm{~Hz}), 2.51(3 \mathrm{H}, \mathrm{s}), 1.469(6 \mathrm{H}, \mathrm{s}) .{ }^{13} \mathrm{C} \mathrm{NMR}(75 \mathrm{MHz}$, DMSO-d $\left.{ }_{6}\right) \delta(\mathrm{ppm}): 157.56,154.89,148.97,154.64,144.47$, 143.44, 142.29, 141.31, 138.88, 137.90, 129.96, 128.05, 127.74, $126.78,119.85,118.63,117.64,115.79,115.64,115.13,115.02$, 41.19, 30.83, 11.59. Anal. Calcd. for $\mathbf{C}_{\mathbf{3 2}} \mathbf{H}_{\mathbf{2 6}} \mathbf{N}_{\mathbf{8}} \mathbf{O}_{12} \mathbf{S}_{3}$ : C, 47.40; H, 3.23; N, 13.82; S, 11.86. Found: C, 47.46; H, 3.31; N, 13.56; S, 11.80 .

2.2.3.6. $6 f\left(\mathrm{C}_{35} \mathrm{H}_{32} \mathrm{~N}_{8} \mathrm{O}_{10} \mathrm{~S}_{2}\right)$. Brown, (83\%). $\lambda_{\max }(\mathrm{nm}): 450$. FTIR (KBr, cm $\left.{ }^{-1}\right) v_{\max }: 3464\left(\mathrm{OH}, \mathrm{NH}\right.$ str.), $2963\left(\mathrm{CH}_{2}\right.$ str.), 1653, 1593 ( $\mathrm{C}=\mathrm{C}$ aromatic), $1490\left(\mathrm{~N}=\mathrm{N}\right.$ str.), 1338 ( $\mathrm{SO}_{3} \mathrm{H}$ str.), 1213, 1153, 1120 (C-C str.), $1002(\mathrm{~S}=\mathrm{O}), 872(\mathrm{Ar}-\mathrm{H}) .{ }^{1} \mathrm{H}$ NMR (300 MHz, DMSO-d 6$) \delta: 11.30(1 \mathrm{H}, \mathrm{s}, \mathrm{O}-\mathrm{H}), 7.94(2 \mathrm{H}$, $\mathrm{d}, J=8.7 \mathrm{~Hz}), 7.82-7.93(1 \mathrm{H}, \mathrm{m}), 7.67(2 \mathrm{H}, \mathrm{d}, J=8.7 \mathrm{~Hz}), 6.98$ $(1 \mathrm{H}, \mathrm{d}, J=9.4 \mathrm{~Hz}), 6.81(1 \mathrm{H}, \mathrm{s}), 6.58(1 \mathrm{H}, \mathrm{d}, J=9.4 \mathrm{~Hz}), 6.42$ $\left(1 \mathrm{H}, \mathrm{s}, \mathrm{SO}_{3} \mathrm{H}\right), 2.47(3 \mathrm{H}, \mathrm{s}) .{ }^{13} \mathrm{C}$ NMR $\left(75 \mathrm{MHz}, \mathrm{DMSO}-\mathrm{d}_{6}\right) \delta$ (ppm): 158.77, 155.9, 147.61, 145.61, 143.86, 143.25, 141.63, $139.81,136.75,130.25,127.91,125.78,119.80,118.31,116.73$, 115.94, 115.23, 11.59. Anal. Calcd. for $\mathbf{C}_{\mathbf{3 5}} \mathbf{H}_{\mathbf{3 2}} \mathbf{N}_{\mathbf{8}} \mathbf{O}_{\mathbf{1 0}} \mathbf{S}_{\mathbf{2}}$ : C, 53.29; H, 4.09; N, 14.21; S, 8.13. Found: C, 53.35; H, 4.13; N, $14.04 ;$ S, 8.20.

\subsection{Dyeing method}

Dye solution $(10 \mathrm{ml}, 0.4 \%, \mathrm{w} / \mathrm{v})$ was taken in a dye-bath. The $\mathrm{pH}$ of the dye-bath was adjusted to 6.5 by adding acetic acid solution $(1.0 \mathrm{ml}, 10 \%, \mathrm{w} / \mathrm{v})$ solution. The total volume of the dye-bath was adjusted to $100 \mathrm{ml}$ by adding required amount of water. The leather swatches were introduced into the dye-bath with stirring. The content of the dye-bath was stirred for $1 \mathrm{~h}$ at $25-30{ }^{\circ} \mathrm{C}$. The temperature was then gradually raised to $55^{\circ} \mathrm{C}$ over period of half hour and maintained for one hour. The dyebath was kept rotating during the process of dyeing. Then $2.0 \mathrm{ml}$ formic acid was added to adjust $\mathrm{pH}$ to 2.0 for dye fixation. After this, the spent dye liquor was taken in $250 \mathrm{ml}$ volumetric flask. The swatches were washed with cold water and the combined solution of dye liquor and washings was then further diluted to $250 \mathrm{ml}$ with water. The absorbance of this solution was measured to find out the exhaustion of dye on leather. The dyed swatches were dried and mounted on shade card. A weighed amount of leather swatch was stirred in boiling acidified pyridine which dissolves the unfixed dye from swatch and from the absorbance of this solution percentage fixation was checked.

\section{Results and discussion}

\subsection{Synthesis and spectral characterization of ligand acid dyes and their metal complexes}

Synthesis of acid dyes and their iron (Fe, II) and copper $(\mathrm{Cu}$, II) complexes were prepared in five step procedure as shown in Scheme 1. SPMP [1-(4-sulphophenyl)3-methyl-2-pyrazolin-5one] was nitrosated at $0-5{ }^{\circ} \mathrm{C}$ using $\mathrm{NaNO}_{2}$ and $\mathrm{HCl}$ as described by Knorr. The nitroso compound was filtered to remove some terry material. The clarified nitroso derivative [that usually exists in an oxime form (as indicated by its FTIR)] was salted out by common salt. It was dried after filtration. Reduction of oxime was carried at $100-105^{\circ} \mathrm{C}$ using zinc and $\mathrm{HCl}$. The oxime and zinc were alternatively added in small portions in boiling $\mathrm{HCl}$ solution. The reduction was completed as the solution became colorless. A small amount of additional zinc dust was also added to prevent aerial oxidation on cooling. The resultant amine hydrochloride was quenched to $-7^{\circ} \mathrm{C}$. The excessive un-reacted zinc was removed by filtration. This amine hydrochloride was diazotized using an aqueous solution of $\mathrm{NaNO}_{2}(6.9 \mathrm{~g}$ dissolved in $250 \mathrm{ml}$ of solution) and $\mathrm{HCl}$ at -5 to $-2{ }^{\circ} \mathrm{C}$ to avoid the formation of Rubazoic acid, which is automatically formed during this reaction with increasing temperature due to oxidizing action of nitrous acid, formed in situ. The diazonium salt prepared in this way was coupled with different para substituted phenols, like, $p$-chlorophenol, $p$-nitrophenol, phenol-4-suphonic acid, 2nitrophenol-4-suphonic acid and bisphenols (bisphenol $\mathrm{S}$ and bisphenol A). The coupling was carried out in alkaline medium at $\mathrm{pH} 8-9$. The synthesis of this diazo has been confirmed from X-ray structure of its crystal. Coupling in alkaline medium occurred at ortho position to the hydroxyl groups of phenol and bisphenol derivatives, as para position was blocked. The synthesized dyes $\mathbf{6 a - f}$ were precipitated on completion of reaction by reducing the $\mathrm{pH}$ of solution to 1.0 with $\mathrm{HCl}$. The filtered dyes were dried and purified in ethanol. Metallization of these dyes was done by treating their alkaline solution with $\mathrm{FeSO}_{4} \cdot 7 \mathrm{H}_{2} \mathrm{O}$ and $\mathrm{CuSO}_{4} \cdot 5 \mathrm{H}_{2} \mathrm{O}$ at $65-70{ }^{\circ} \mathrm{C}$. It took about $4-5 \mathrm{~h}$ to complete the metallization as was observed by taking the TLC of reaction mixture in 9:1 chloroform and methanol. Dyes (7a-l) were precipitated with addition of $\mathrm{HCl}$, filtered and dried in oven at $80^{\circ} \mathrm{C}$. These dyes were again purified from ethanol, dried, weighed and determined the percentage yield. These unmetallized dyes $\mathbf{6 a - f}$ are tridentate ligands which form complexes with iron $(\mathrm{Fe}, \mathrm{II})$ and copper $(\mathrm{Cu}, \mathrm{II})$ through 1:1 metal and ligand stoichiometric ratio (Fig. 2). In case of $\mathrm{Fe}^{2+}$ and $\mathrm{Cu}^{2+}$ complexes lone pairs of electrons are donated by two oxygen atoms and one nitrogen atom of the diazo linkage, while the other three coordination numbers of these metals have been satisfied by three water molecules. The complex formation pattern has been verified by the UV-vis spectrophotometric studies of these dyes 7a-l. In case of IR spectra of compounds different moieties showed stretching and bending bands characteristic 


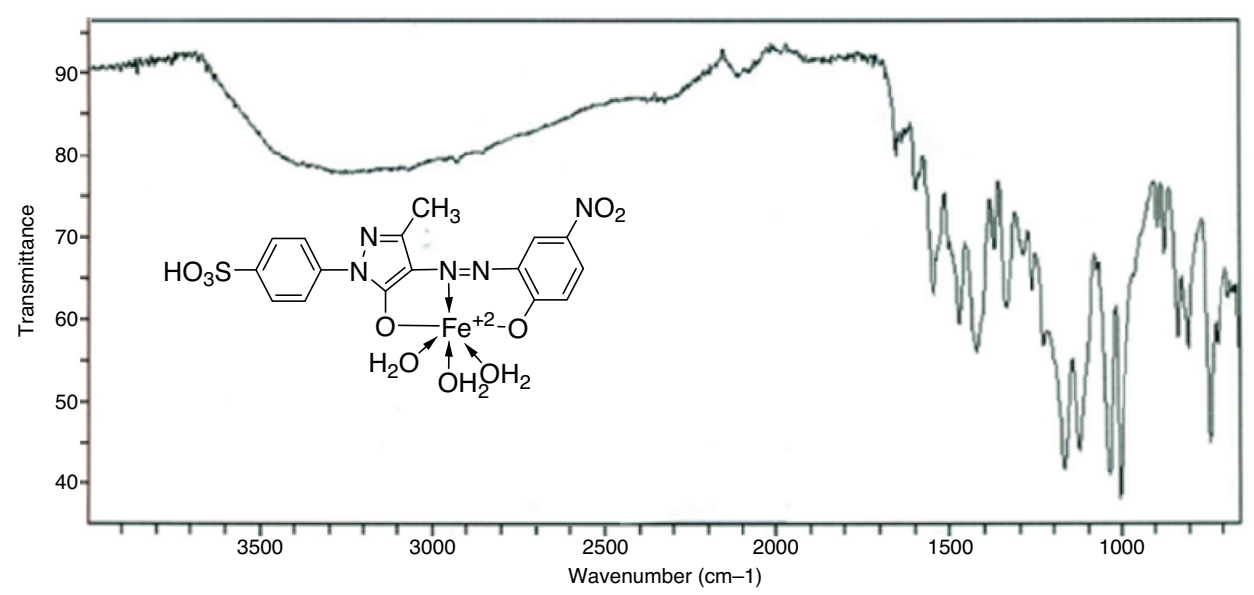

Fig. 1. FTIR spectrum of Iron complex of dye $\mathbf{6} \mathbf{b}$.

of the synthesized compounds. The infrared spectra of the synthesized acid dyes and their metal complexes exhibited absorption peaks due to $\mathrm{O}-\mathrm{H}, \mathrm{Ar}-\mathrm{H}, \mathrm{C}-\mathrm{H}, \mathrm{C}=\mathrm{O}, \mathrm{C}=\mathrm{C}, \mathrm{N}=\mathrm{N}$, $\mathrm{SO}_{3} \mathrm{H}, \mathrm{C}-\mathrm{O}$ and $\mathrm{O}-\mathrm{M}$ stretching and bending vibrations at 3399 , $3050,2926,1550,1472,1272,1164,1004,834,610 \mathrm{~cm}^{-1}$ as depicted from their FTIR spectra (Fig. 1). Similarly other metal complexes have been confirmed from their respective IR spectra.

${ }^{1} \mathrm{H}$ NMR and ${ }^{13} \mathrm{C}$ NMR spectra were taken for ligand dyes which showed characteristic signals for different protons and carbons at different positions which evidenced the synthesis of dyes. In case of compounds $\mathbf{6 b}$ signal for hydroxyl group was absent due to exchangeable proton with DMSO. The doublet signal of mutually coupled set of four protons of phenyl group substituted with sulfonic group at present 7.95 and $7.68 \mathrm{ppm}$ having coupling constant respectively signals $8.6 \mathrm{~Hz}$. The multiplet signal for one proton of aromatic ring of coupling moiety is present at 7.83-7.90 ppm while the same ring bearing another single proton shows signal at $8.07 \mathrm{ppm}$ with coupling constant $2.35 \mathrm{~Hz}$ which evidenced the meta relationship with another proton at the same ring. The methyl group present at pyrazolone ring exhibited singlet signal at $2.20 \mathrm{ppm}$ (Fig. 2). In ${ }^{13} \mathrm{C}$ NMR spectrum the signal for methyl group is present at $12.14 \mathrm{ppm}$. There are ten signals in the range $117.06-158.00$ ppm for different carbon nuclei in the compound (Fig. 3). In this way other ligand acid dyes were confirmed from their respective ${ }^{1} \mathrm{H}$ NMR and ${ }^{13} \mathrm{C}$ NMR spectra. When the ${ }^{1} \mathrm{H}$ NMR spectra of metal complex dyes were conducted they showed very broad and distorted signals due to paramagnetic nature of metals used for complexation and the so the NMR study of complexes was not fruitful for structure elucidation but in other words the distorted broad signals proved the complexation when the ${ }^{1} \mathrm{H}$ NMR of ligands acid dyes and complexes were compared.

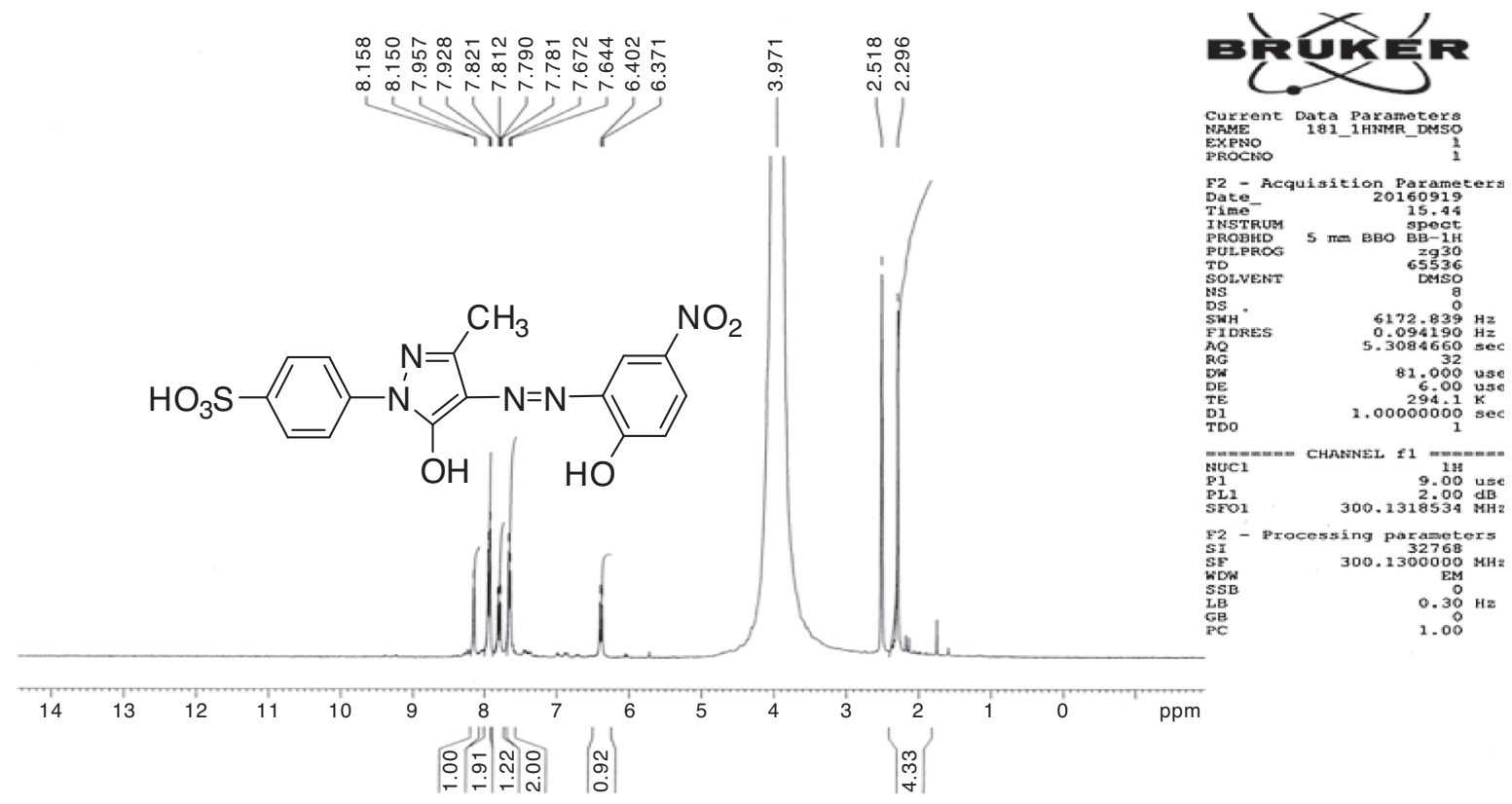

Fig. 2. ${ }^{1} \mathrm{H}$ NMR spectrum of ligand acid dye $\mathbf{6 b}$. 


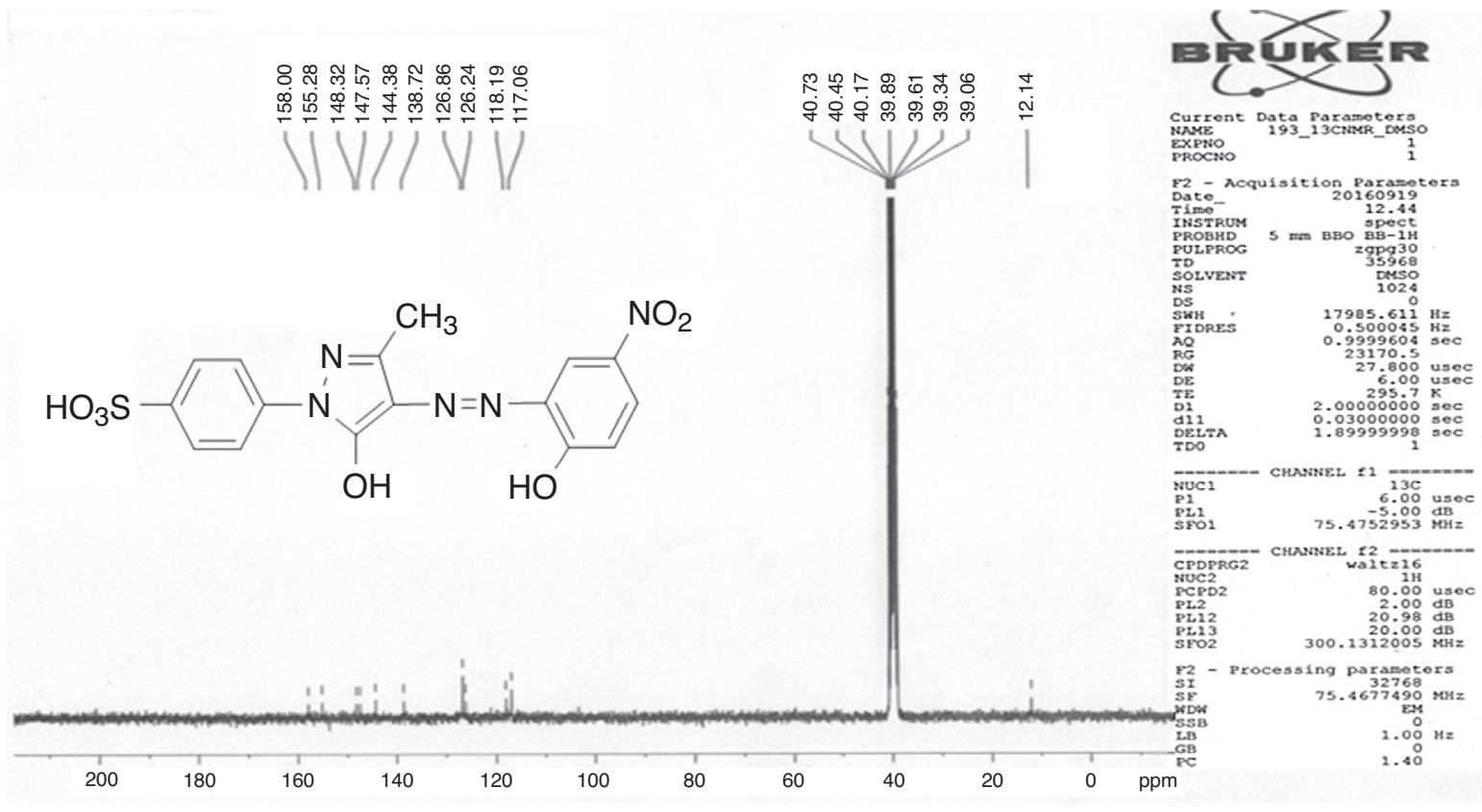

Fig. $3 .{ }^{13} \mathrm{C}$ NMR spectrum of ligand acid dye $\mathbf{6 b}$.

\subsection{Dyeing properties of substituted ligand acid dyes and their metal complexes (6a-f and $7 a-l)$}

The dyeing properties of $p$-substituted phenols and bis phenol dyes have been found to be very attractive. Almost all properties have been found to be of very high value (4-5). Ligand dyes had low values as per our expectation due to the presence of free hydroxyl groups. The dyeing properties of these dyes are given in Table 1.

Almost all un-metalized $p$-substituted phenol dyes have been found to be different; both in $2 \%$ and $5 \%$ dyed leathers, along with a variation of the depth of shades. This can be attributed to the difference of chromophoric systems in all dyes. However, it is clear from shades that this difference is due to the difference of $p$-substituents in different phenols. All of the phenol homologues had dark and redder shades except $p$-sulphophenol substituted dyes. The variation of the depth can be attributed to the participation of peripheral group's variation in different phenols.

Almost all iron-metalized phenol dyes had been found to be similar (olive); both in $2 \%$ and $5 \%$ dyed leathers, along with a variation of depth of shades. However, it is clear from shades that the depth difference is due to the difference of $p$-substituents in different phenols. All the phenol homologues had dark and redder shades except $p$-sulphophenol. Both nitro phenols had similar shades with yellowish tone. Almost all copper-metalized phenol had been found to be different; both in $2 \%$ and $5 \%$ dyed leathers, along with a variation of depth of shades. This can be attributed to the difference of chromophoric systems in all dyes. However, it is clear from shades that this difference is due to the difference of $p$-substituents in different phenols. All of the phenol homologues had dark and redder shades except $p$-sulphophenol. Both nitro phenols had similar shades with yellowish red tone.

The dyeing properties of bis-phenols dyes have been found to be very good and attractive. Almost all properties have been found to be of very high value (4-5). The dyes with bisphenol-A have been found to be much darker as compared to the dyes of bisphenol-S. This can be attributed to the $n \rightarrow \Pi^{*}$ electronic transitions occurring in sulphone group of bisphenol-S.

As it is clear from dye shades among the un-metalized bisphenol dyes, the dye with bisphenol-A had a high color value while bisphenol-S dye gave a low color yield on leather. This difference can be ascribed to the participation of sulphone group present in bisphenol-S.

It is clear from the depth of shades that iron metalized bisphenol dyes had greater color value than their parent un-metalized bisphenol dyes. These dyes are much greener as they were expected. The iron complex with ligand acid dye based on bisphenol-S had a low color value while bisphenol-A dye provided a darker shade and high color yield on leather along with a much redder effect. This difference can be attributed to the participation of sulphone group in bisphenol-S.

Similarly, copper metalized bisphenol dyes had also greater color value than their parent un-metalized bisphenol dyes. These dyes are much redder as per our expectation. The copper complex dye with bisphenol-A had a high color value while bisphenol-S dye gave a lighter and low color yield on leather along with a much redder effect. This difference can be attributed to the participation of sulphone group in bisphenol-S (Figs. 4 and 5). 
Table 1

Fastness properties of ligand acid dyes (6a-f) and their metal complexes (7a-l).

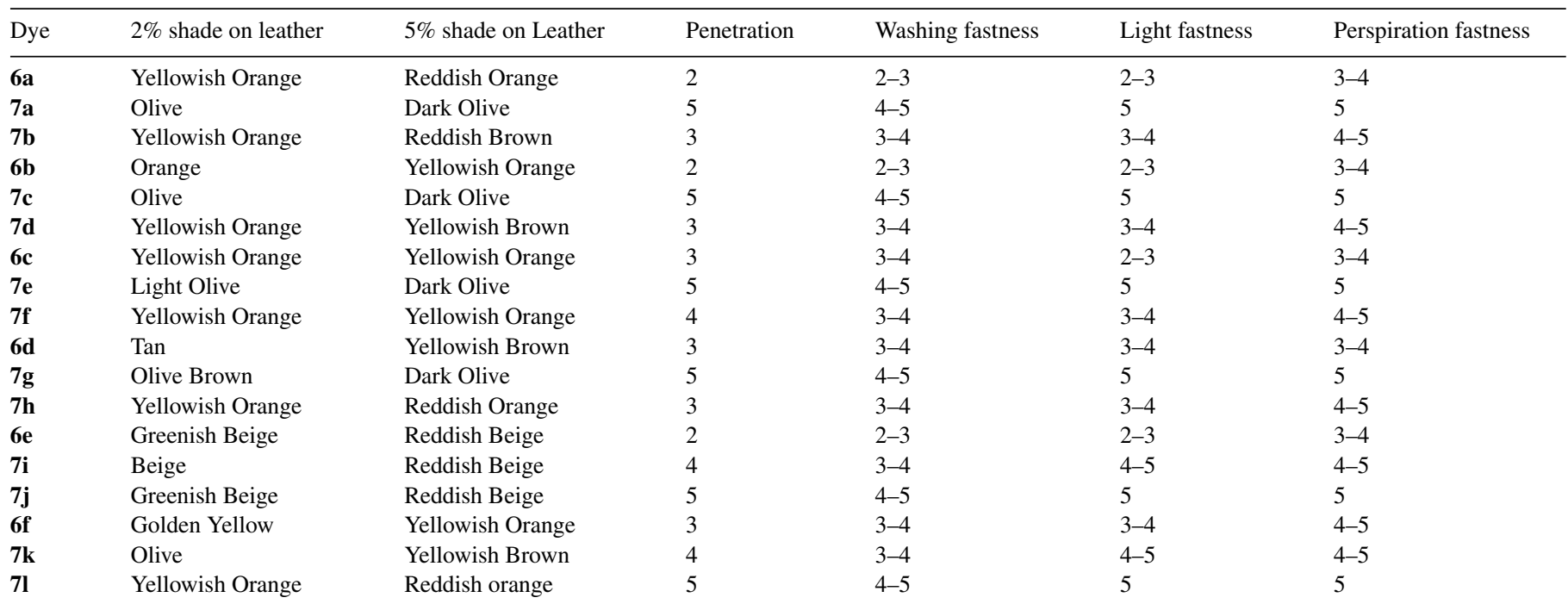

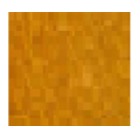

$6 a$

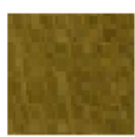

$7 a$

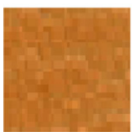

$7 \mathrm{~b}$

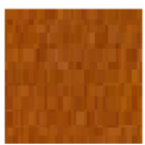

$6 a$

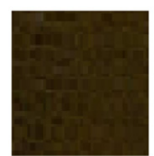

$7 a$

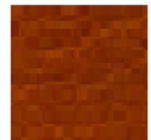

$7 b$

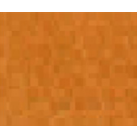

$6 b$

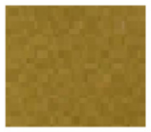

$7 c$

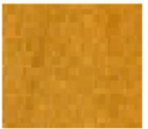

$7 d$

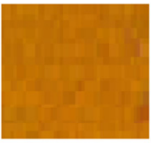

$6 b$

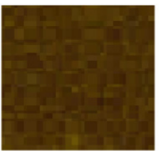

$7 c$

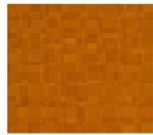

$7 d$

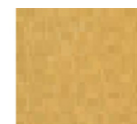

$6 c$

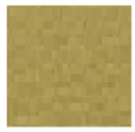

$7 e$

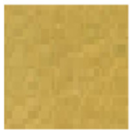

$7 f$

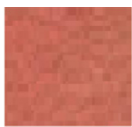

$6 d$

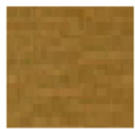

$7 g$

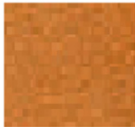

$7 \mathrm{~h}$

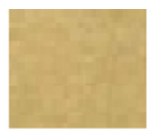

$6 e$

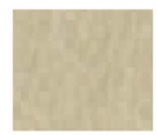

$7 i$

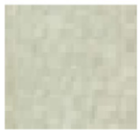

$7 \mathrm{j}$
7I

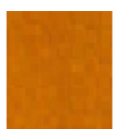

$6 f$

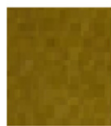

$7 k$

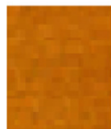

Fig. 4. $2 \%$ shade of dyes $\mathbf{6 a - f}$ and $7 \mathbf{a}-\mathbf{l}$ on leather.

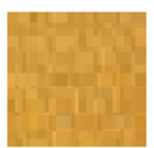

$6 c$

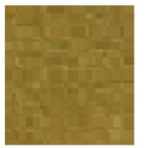

$7 e$

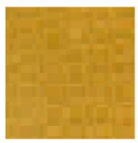

$7 f$

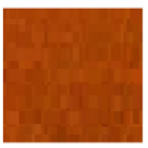

$6 d$

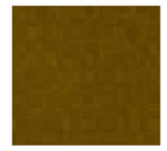

$7 g$

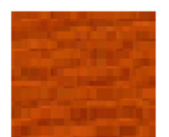

$7 \mathrm{~h}$

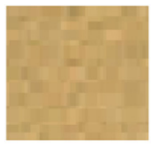

$6 e$

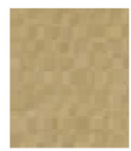

$7 i$

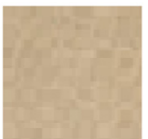

7j 
Table 2

$\mathrm{UV}-\mathrm{vis}$ data of ligand acid dyes (6a-f) and their Fe (II) and $\mathrm{Cu}(\mathrm{II})$ complexes (7a-l).

\begin{tabular}{|c|c|c|c|c|}
\hline Dye & Molecular formula & Molecular mass & Powder/solution color & $\lambda_{\max }(\mathrm{nm})$ \\
\hline $6 \mathbf{a}$ & $\mathrm{C}_{16} \mathrm{H}_{13} \mathrm{ClN}_{4} \mathrm{O}_{5} \mathrm{~S}$ & 408.82 & Orange/Reddish Orange & 460 \\
\hline $7 \mathbf{a}$ & $\mathrm{C}_{16} \mathrm{H}_{17} \mathrm{ClFeN}_{4} \mathrm{O}_{8} \mathrm{~S}$ & 516.69 & Olive/Olive Brown & 490 \\
\hline $7 \mathbf{b}$ & $\mathrm{C}_{16} \mathrm{H}_{13} \mathrm{ClCuN}_{4} \mathrm{O}_{6} \mathrm{~S}$ & 488.36 & Tan/Reddish Violet & 500 \\
\hline $6 \mathbf{b}$ & $\mathrm{C}_{16} \mathrm{H}_{13} \mathrm{~N}_{5} \mathrm{O}_{7} \mathrm{~S}$ & 419.37 & Dark Brown/Reddish Orange & 480 \\
\hline $7 c$ & $\mathrm{C}_{16} \mathrm{H}_{17} \mathrm{Fe} \mathrm{N} \mathrm{N}_{5} \mathrm{O}_{10} \mathrm{~S}$ & 527.24 & Gray/Yellowish Brown & 440 \\
\hline 7d & $\mathrm{C}_{16} \mathrm{H}_{13} \mathrm{Cu} \mathrm{N}{ }_{5} \mathrm{O}_{8} \mathrm{~S}$ & 498.91 & Tan/Reddish Yellow & 460 \\
\hline 6c & $\mathrm{C}_{16} \mathrm{H}_{14} \mathrm{~N}_{4} \mathrm{O}_{8} \mathrm{~S}_{2}$ & 454.43 & Orange/Yellowish Orange & 460 \\
\hline $7 e$ & $\mathrm{C}_{16} \mathrm{H}_{18} \mathrm{FeN}_{4} \mathrm{O}_{11} \mathrm{~S}_{2}$ & 562.31 & Olive Brown/Yellowish Brown & 430 \\
\hline $7 f$ & $\mathrm{C}_{16} \mathrm{H}_{14} \mathrm{CuN}_{4} \mathrm{O}_{9} \mathrm{~S}_{2}$ & 533.98 & Brown/Yellowish Orange & 460 \\
\hline 6d & $\mathrm{C}_{16} \mathrm{H}_{13} \mathrm{~N}_{5} \mathrm{O}_{10} \mathrm{~S}_{2}$ & 499.43 & Orange/Reddish Orange & 520 \\
\hline $7 \mathrm{~g}$ & $\mathrm{C}_{16} \mathrm{H}_{17} \mathrm{FeN}_{5} \mathrm{O}_{13} \mathrm{~S}_{2}$ & 607.31 & Gray/Yellowish Orange & 470 \\
\hline $7 \mathbf{h}$ & $\mathrm{C}_{16} \mathrm{H}_{13} \mathrm{CuN}_{5} \mathrm{O}_{11} \mathrm{~S}_{2}$ & 578.98 & Tan/Reddish Brown & 500 \\
\hline $6 e$ & $\mathrm{C}_{32} \mathrm{H}_{26} \mathrm{~N}_{8} \mathrm{O}_{12} \mathrm{~S}_{3}$ & 810.79 & Orange/Reddish Orange & 420 \\
\hline $7 \mathbf{i}$ & $\mathrm{C}_{32} \mathrm{H}_{34} \mathrm{Fe}_{2} \mathrm{~N}_{8} \mathrm{O}_{18} \mathrm{~S}_{3}$ & 1026.54 & Brown/Reddish Brown & 360 \\
\hline $7 \mathbf{j}$ & $\mathrm{C}_{32} \mathrm{H}_{29} \mathrm{Cu}_{2} \mathrm{~N}_{8} \mathrm{O}_{14} \mathrm{~S}_{3}$ & 1008.93 & Tan/Yellow & 370 \\
\hline $6 \mathbf{f}$ & $\mathrm{C}_{35} \mathrm{H}_{32} \mathrm{~N}_{8} \mathrm{O}_{10} \mathrm{~S}_{2}$ & 788.81 & Brown/Yellowish Orange & 450 \\
\hline $7 \mathbf{k}$ & $\mathrm{C}_{35} \mathrm{H}_{40} \mathrm{Fe}_{2} \mathrm{~N}_{8} \mathrm{O}_{16} \mathrm{~S}_{2}$ & 1004.56 & Gray/Reddish brown & 440 \\
\hline 71 & $\mathrm{C}_{35} \mathrm{H}_{32} \mathrm{Cu}_{2} \mathrm{~N}_{8} \mathrm{O}_{12} \mathrm{~S}_{2}$ & 735.44 & Dark Brown/Yellowish Orange & 450 \\
\hline
\end{tabular}

\subsection{Optical studies of dyes}

In case of optical studies, dyes were conducted their UV-vis studies to observe the changes rendered by metal complex formation. The UV-vis data presented in Table 2 is supported by combined UV-vis spectra of ligand acid dyes $\mathbf{6 a - f}$. The un-metalized dye-6a was an orange dye with $\lambda_{\max } 460 \mathrm{~nm}$ while on metallization of this with iron, Olive Brown dye (Dye-7a) was produced with $\lambda_{\max } 490 \mathrm{~nm}$ undergoing a bathochromic shift of $30 \mathrm{~nm}$ along with hypochromic effect. Metallization of dye $\mathbf{6 a}$ with copper resulted in the formation of a Reddish Violet dye (Dye-7b) with $\lambda_{\max } 500 \mathrm{~nm}$ and showed a bathochromic shift of $40 \mathrm{~nm}$ with hypochromic shift in intensity.

Three dyes were prepared with $p$-nitrophenol. The first one being an un-metalized dye and the other two were iron and copper complexes, respectively. The detailed properties of $p$ nitrophenol dyes are given in Table 1 . The unmetallized dye 6b was an orange dye with $\lambda_{\max } 480 \mathrm{~nm}$ which developed yellowish brown dye on complexation with iron (Dye 7c) with $\lambda_{\max } 440 \mathrm{~nm}$. It showed hypsochromic shift of $40 \mathrm{~nm}$ along with hyperchromic effect. Similar behavior was observed for copper complexes of this dye. The dye $\mathbf{6 c}$ was prepared from phenol-4-sulphonic acid which was Yellowish Orange colored dye having $\lambda_{\max } 460 \mathrm{~nm}$. Metallization of the dye $\mathbf{6 c}$ with iron and copper produced yellowish brown (Dye 7e) and Reddish Orange dye (Dye 7f) dyes with $\lambda_{\max } 430$ and $460 \mathrm{~nm}$ respectively which exhibited pattern of hypso and hypochromic effects. Dyes $7 \mathrm{~g}$ and $7 \mathrm{~h}$ were iron and $\mathrm{Cu}$ complexes of 1:1 type of dye 6d. The un-metalized dye $\mathbf{6 d}$ was a Reddish Orange dye with $\lambda_{\max } 520 \mathrm{~nm}$. Its metallization with Iron produced a yellowish brown dye (Dye 7g) with $\lambda_{\max } 470 \mathrm{~nm}$ and enhanced the absorbance intensity than parent dye and showed a hypsochromic shift of $50 \mathrm{~nm}$. While metallization of the same with copper resulted in the formation of a Reddish Brown dye (Dye $7 \mathbf{h}$ ) with $\lambda_{\max } 500 \mathrm{~nm}$ and a hypsochromic shift of $20 \mathrm{~nm}$ was observed.
In the bisphenol series six dyes were prepared. For this purpose two different bisphenols, namely 4,4'-dihydroxy biphenyl sulphone (BPS), 4, 4'-dihydroxy biphenyl propane (BPA), were used as couplers. Three disazo dyes were accomplished with bisphenol-S. The first dye being an un-metalized one and another two were iron and copper bis-metal complexes, respectively. The un-metalized dye $6 \mathbf{6}$ was a Reddish Orange dye with $\lambda_{\max }$ $420 \mathrm{~nm}$. Its metallization with iron produced a Reddish Brown dye (Dye 7i) with $\lambda_{\max } 410 \mathrm{~nm}$ and a hypsochromic shift of $10 \mathrm{~nm}$ was seen. While the metallization of same dye $\mathbf{6 e}$ with copper resulted in the formation of a Yellow dye (Dye 7j). It had $\lambda_{\max } 370 \mathrm{~nm}$ and absorbance 1.6, showed a hypsochromic shift of $50 \mathrm{~nm}$. The metal complexes of dye $\mathbf{6 f}$ with iron and copper exhibited the similar behavior like bisphenol S dye metal complexes in absorption intensity while no conceivable change was found in $\lambda_{\max }$ position. From the detailed UV-vis study of dyes it was gathered that metal complexes of ligand dyes bearing electron with drawing groups showed hypsochromic shit and those having electron donating groups showed bathochromic shift in absorbance which is in accordance with well established UV-vis absorption pattern of compounds (Figs. 6 and 7).

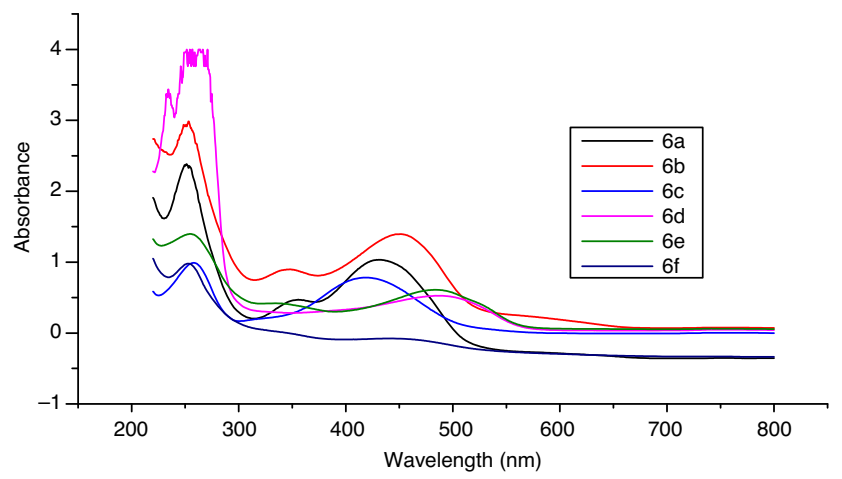

Fig. 6. UV-vis spectrum of ligand acid dyes $\mathbf{6 a - f}$. 

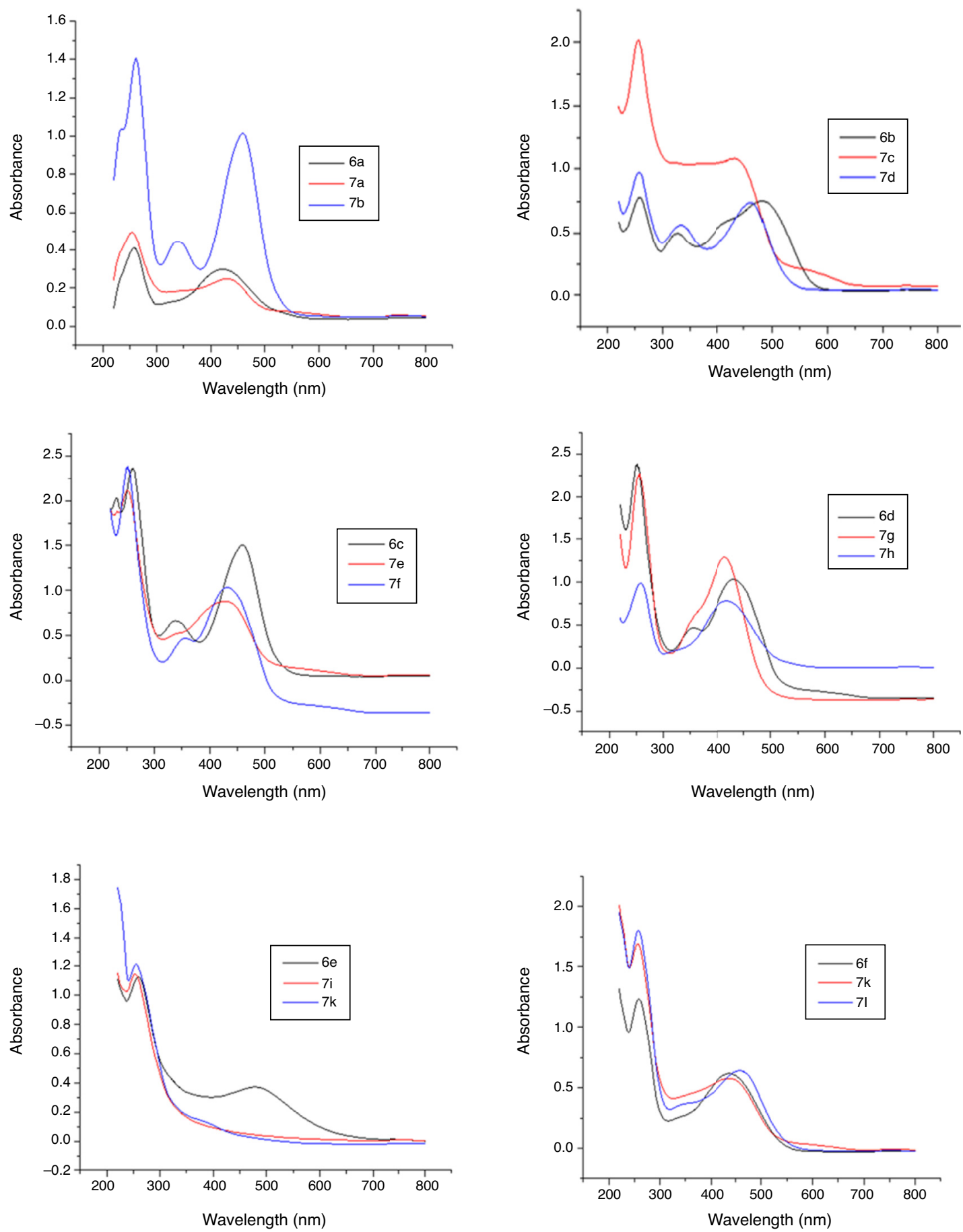

Fig. 7. Effect of metal ions on $\lambda_{\max }$ of ligand acid dyes $\mathbf{6 a - f}$.

\section{Conclusions}

A series of new acid dyes 6a-f and their metal complexes (7a-l) have been synthesized in high yields from 1-( $p$ sulphophenyl)-3-methyl-4-aminopyrazolone with $p$-substituted phenols and bisphenols. Metal complexation has changed the absorption maxima of acid dyes which resulted in hypsochromic shift in iron and copper complexes of those acid dyes which carried electron withdrawing groups like nitro and sulfonic while iron and copper complexes of dyes bearing electron donating groups caused bathochromic shifts. Moreover, metal complex dyes had better application properties on leather as compared to ligand dyes due to elevated substantivity owing to electron deficient metals and polar substituents.

\section{Conflict of interest}

The authors have no conflicts of interest to declare. 


\section{Appendix A. Supplementary data}

Supplementary data associated with this article can be found, in the online version, at doi:10.1016/j.jart.2017.03.002.

\section{References}

Abdalla, N. A., El-Haty, M. T., Adam, F. A. E., \& Hassan, F. W. (2013). Complexes of $\mathrm{Cu}$ (II), Co (II), Ni (II), Zn (II), Zr (IV), Ce (III), La (III) AND UO2 (II) with arylazo pyriimidine derivatives. Revue Roumaine de Chimie, 58(11-12), 899-913.

Abe, T., Mano, S., Yamaya, Y., \& Tomotake, A. (1999). Thermal dye transfer printing with chelate compounds. Journal of Imaging Science and Technology, 43(4), 339-344.

Almeida, M. R., Stephani, R., Dos Santos, H. F., \& Oliveira, L. F. C. D. (2009). Spectroscopic and theoretical study of the "azo"-dye E124 in condensate phase: evidence of a dominant hydrazo form. Journal of Physical Chemistry A, 114(1), 526-534.

Amin, A. S., Mohammed, T. Y., \& Mousa, A. A. (2003). Spectrophotometric studies and applications for the determination of yttrium in pure and in nickel base alloys. Spectrochimica Acta Part A: Molecular and Biomolecular Spectroscopy, 59(11), 2577-2584.

Dharmalingam, V., Ramasamy, A. K., \& Balasuramanian, V. (2011). Synthesis and EPR studies of copper metal complexes of dyes derived from Remazol Red B, Procino Yellow, Fast Green FCF, Brilliant Cresyl Blue with Copper Acetate Monohydrate. Journal of Chemistry, 8(S1), S211-S224.

Goftar, M. K., Moradi, K., \& Kor, N. M. (2014). Spectroscopic studies on aggregation phenomena of dyes. European Journal of Experimental Biology, 4(2), $72-81$.
Kirkan, B., \& Gup, R. (2008). Synthesis of new azo dyes and Copper (II) complexes derived from barbituric acid and 4-aminobenzoylhydrazone. Turkish Journal of Chemistry, 32(1), 9-17.

Kocaokutgen, H., Erdem, E., \& Gümrükçgüoglu, I. E. (1998). Synthesis of HMFAN and its chromium and cobalt complexes and their application on nylon 6 and wool. Journal of the Society of Dyers and Colourists, 114(3), 93-95.

Maradiya, H. R., \& Patel, V. S. (2002). Thiophene based monoazo disperse dyes for polyester fabric. Journal of the Serbian Chemical Society, 67(1), 17-26.

Otutu, J. O. (2013). Synthesis and application of azo dyes derived from 2amino-1, 3, 4-thiadiazole-2-thiol on polyester fibre. International Journal of Research and Reviews in Applied Sciences, 15(2), 292-296.

Patel, D. R., \& Patel, K. C. (2011). Synthesis of some new thermally stable reactive dyes having $4(3 \mathrm{H})$-quinazolinone molecule for the dyeing of silk, wool, and cotton fibers. Fibers and Polymers, 12(6), 741-752.

Radulescu-Grad, M. E., Muntean, S. G., Todea, A., Verdes, O., \& Andelescu, A. (2015). Synthesis and characterization of new metal complex dye. Chemical Bulletin of Politehnica University of Timisoara, 60(74), 37-40.

Sakoma, K. J., Bello, K. A., \& Yakubu, M. K. (2012). Synthesis of some azo disperse dyes from 1-substituted 2-hydroxy-6-pyridone derivatives and their colour assessment on polyester fabric. Open Journal of Applied Sciences, 2(01), 54-59

Seferoğlu, Z. (2009). A study on tautomeric equilibria of new hetarylazo-6aminouracils. Arkivoc, 7, 42-57.

Sekar, N. (1999). Ecofriendly metal complex dyes - An update. Colourage, 46, 63-65.

Wang, S., Shen, S., \& Xu, H. (2000). Synthesis, spectroscopic and thermal properties of a series of azo metal chelate dyes. Dyes and Pigments, 44(3), 195-198.

Weglarz-Tomczak, E., \& Gorecki, L. (2012). Azo dyes - Biological activity and synthetic strategy. Chemik, 66(12), 1298-1307. 